\title{
A EDUCAÇÃO EM TEMPO INTEGRAL NAS PRINCIPAIS LEGISLAÇÕES EDUCACIONAIS BRASILEIRAS
}

\author{
Gustavo Antônio Valentim, Vanda Moreira Machado Lima \\ Universidade Estadual Paulista - UNESP, Programa de Pós-Graduação em Educação, Presidente Prudente/SP, E-mail: \\ gustavoantonio.valentim@gmail.com. Agência de fomento: CAPES
}

\section{RESUMO}

Neste trabalho buscamos identificar a maneira como a educação em tempo integral é tratada em algumas das legislações educacionais brasileiras. Tal investigação corresponde a uma etapa de uma pesquisa de mestrado que tem como objetivo investigar e analisar a criação do Programa de Ensino Integral pelo governo estadual paulista e como o contexto histórico, político, econômico e social influenciou sua configuração. Utilizando a metodologia da análise documental examinamos as Diretrizes Curriculares Nacionais Gerais para a Educação Básica; a Lei de Diretrizes e Bases da Educação Nacional (LDB/96) e o Plano Nacional de Educação (PNE/14). Constatamos que a educação em tempo integral foi abordada em todas as legislações e que a ênfase ao tratar desta modalidade de ensino nos textos legais foi ampliando com o passar do tempo, tanto que, o $\mathrm{PNE} / 14$ lhe concede um tratamento mais apurado que as demais legislações.

Palavras-Chave: Educação em Tempo Integral, Análise Documental, Legislações Educacionais.

\section{THE FULL-TIME EDUCATION IN THE MAIN BRAZILIAN EDUCATIONAL LEGISLATION}

\begin{abstract}
In this work we seek to identify the way in which full-time education is treated in some of the Brazilian educational legislation. This research corresponds to a stage of a master's research that aims to investigate and analyze the creation of the Integral Education Program by the state government of São Paulo and how the historical, political, economic and social context influenced its configuration. Using the methodology of documentary analysis, we analyzed the Diretrizes Curriculares Nacionais Gerais para a Educação Básica; a Lei de Diretrizes e Bases da Educação Nacional (LDB/96) e o Plano Nacional de Educação (PNE/14). We find that full-time education has been addressed in all legislations and that the emphasis on addressing this type of teaching in legal texts has increased over time, so much so that PNE/14 gives it a more accurate treatment than other Legislation.
\end{abstract}

Keywords: Full-Time Education, Documentary Analysis, Educational Legislation. 


\section{INTRODUÇÃO}

Dentre as discussões acerca do sistema educacional brasileiro ao longo do tempo destacamos neste trabalho a Educação em Tempo Integral, visto que, atualmente esse tema se faz presente no cenário educacional brasileiro, principalmente como proposta para melhorar a qualidade da educação.

Segundo Esquinsani (2008, p.2) "Pode-se buscar a gênese da escolarização em turno integral no Brasil junto ao movimento escolanovista, influenciado pelo pragmatismo e pelo pensamento de John Dewey". Sobre as experiências com este modelo de ensino no Brasil a autora afirma que:

Ainda dentro da leitura pragmatista de Dewey e da escola nova, o primeiro educador brasileiro a defender a ideia da escola de turno integral como possibilidade qualitativa da escola pública foi o baiano Anísio Spínola Teixeira [...] o primeiro educador a discutir a possibilidade (e concretizar tal proposta) de escolas em turno integral para educar a população. (ESQUINSANI, 2008, p. 2)

Após a experiência de Anísio Teixeira com o Centro Educacional Carneiro Ribeiro em Salvador/ BA, surgiram outras experiências de educação em tempo integral no Brasil, porém, de maneira desconexa e descontinua. Esquinsani (2008) destaca como experiências mais relevantes, os Ginásios Vocacionais instaurados pelo governo estadual paulista nos anos de 1960; os Centros Integrados de Educação Pública (CIEPs) instaurados pelo governo estadual do Rio de Janeiro nos anos de 1980 e 1990; e os Centros de Atenção Integral à criança e ao adolescente (CAICs) implementados pelo governo federal nos anos de 1990.

Neste aspecto, Coelho (2008) avalia a Educação Integral como um tema recorrente, pois, vem à discussão de tempos em tempos, mas nem sempre se consolida em políticas públicas. Entretanto, existem diferentes justificativas para a ampliação da jornada escolar.

A ampliação do tempo diário de escola pode ser entendida e justificada de diferentes formas: (a) ampliação do tempo como forma de se alcançar melhores resultados da ação escolar sobre os indivíduos, devido à maior exposição desses às práticas e rotinas escolares; (b) ampliação do tempo como adequação da escola às novas condições da vida urbana, das famílias e particularmente da mulher; (c) ampliação do tempo como parte integrante da mudança na própria concepção de educação escolar, isto é, no papel da escola na vida e na formação dos indivíduos. (CAVALIERE, 2007, p. 1016)

O Estado de São Paulo conta com a maior rede de escolas do país e implementou diversas experiências em tempo integral ao longo do tempo. Desde 2006, existem as Escolas de Tempo Integral (ETI). Ainda assim, a Secretaria de Educação de São Paulo (SEE/SP), em 2012 criou o Programa de Ensino Integral (PEI) instaurado pela Lei Complementar no 1.164/12 (SÃO PAULO, 2012). Tal programa se configura como nosso objeto de estudo em uma pesquisa de mestrado que tem como objetivo investigar e analisar a criação do Programa de Ensino Integral pelo governo estadual paulista e como o contexto histórico, político, econômico e social influenciou sua configuração, buscando compreender que política educacional é essa que foi criada a luz deste cenário.

Este trabalho contém uma das etapas já concluídas desta pesquisa de mestrado. Nele apresentaremos os resultados de uma investigação que objetivou identificar a maneira como a educação em tempo integral é tratada em algumas legislações educacionais brasileiras. 


\section{METODOLOGIA}

Esta investigação foi pautada nos pressupostos da pesquisa qualitativa e o estudo dos documentos legais seguiu os procedimentos metodológicos da análise documental. O processo de pesquisa teve início com a seleção das legislações a serem trabalhadas, segundo Cellard (2010, p. 296) esta é uma etapa de grande importância para o sucesso do trabalho, pois, o pesquisador "[...] deve localizar os textos pertinentes e avaliar a sua credibilidade, assim como a sua representatividade. [...]".

Seguindo esta linha, dentre as legislações que regem a educação nacional selecionamos como recorte para esta pesquisa a principal lei que rege a educação nacional, a Lei no 9.394 de 20 de dezembro de 1996 (LDB/96); as Diretrizes Curriculares Nacionais Gerais para a Educação Básica, Resolução no 4, de 13 de julho de 2010 e o plano que determina as diretrizes, metas e estratégias que regem a educação nacional no decênio de 2014 a 2024, o Plano Nacional de Educação (PNE/14), Lei no 13.005, de 25 de junho de 2014.

Cellard (2010) define que antes de iniciarmos a análise documental propriamente dita é necessário realizarmos uma análise preliminar dos documentos selecionados. Nesta análise preliminar o texto deve ser examinado levando em conta cinco dimensões: o contexto; o autor ou autores; a autenticidade e a confiabilidade do texto; a natureza do texto; e os conceitos-chave e a lógica interna do texto. Esta etapa nos proporcionou uma maior clareza de informações e, foi relevante na análise dos documentos.

Após a seleção e a análise preliminar partimos para a análise das legislações, segundo Cellard (2010, p. 303) este

[...] é o momento de reunir todas as partes - elementos da problemática ou do quadro teórico, contexto, autores, interesses, confiabilidade, natureza do texto, conceitos-chave. O pesquisador poderá, assim, fornecer uma interpretação coerente, tendo em conta a temática ou o questionamento inicial. [...]

Portanto, realizamos nosso exame buscando identificar em que partes do texto a educação em tempo integral se fez presente e de que maneira ela foi abordada.

\section{RESULTADOS}

O movimento de elaboração da atual Lei de Diretrizes e Bases da Educação Nacional, Lei no 9.394 de 20 de dezembro de 1996 (LDB/96), teve início em 1987 com conferência de Demerval Saviani na $X$ Reunião Anual da Associação Nacional de Pesquisa e Pós-graduação em Educação (ANPEd), em Salvador. Daí em diante, foram quase 10 anos de debates e disputas políticas econômicas e sociais por diferentes setores e atores, que perpassaram os governos dos presidentes José Sarney, Fernando Collor de Mello e Itamar Franco, até sua promulgação, em 1996, no governo de Fernando Henrique Cardoso. Estiveram à frente do Ministério da Educação ( $\mathrm{MEC})$, neste período, os ministros Jorge Konder Bornhausen, Aloísio Guimarães Sotero, Hugo Napoleão do Rego Neto, Carlos Corrêa de Menezes Sant'anna, Carlos Alberto Chiarelli, José Goldemberg, Eraldo Tinoco Melo, Murílio de Avellar Hingel e Paulo Renato Souza, respectivamente.

Dois projetos foram submetidos para apreciação do Congresso Nacional, tendo sido aprovado, em 17/12/96 e, promulgado em 20/12/96, o projeto do senador Darcy Ribeiro no qual observa-se força do Ministério da Educação (MEC) e da iniciativa privada.

Os temas tratados na LDB/96, estão divididos em 9 títulos compostos por 92 artigos, que versam: o Título I trata "Da Educação"; o Título II trata "Dos Princípios e Fins da Educação Nacional"; o Título III "Do Direito à Educação e do Dever de Educar"; o Título IV trata "Da Organização da Educação Nacional"; o Título V que trata "Dos Níveis e das Modalidades de 
Educação e Ensino" é dividido em cinco capítulos, o Capítulo I trata "Da Composição dos Níveis Escolares; o Capítulo II que trata "Da Educação Básica"; o Capítulo III trata "Da Educação Profissional"; o Capítulo IV trata "Da Educação Superior" e o Capítulo V que trata "Da Educação Especial"; o Título VI trata "Dos Profissionais da Educação"; o Título VII "Dos Recursos financeiros"; o Título VIII trata "Das Disposições Gerais" e o Título IX trata "Das Disposições Transitórias".

No tocante a educação em tempo integral, a LDB/96 aborda esta modalidade de ensino no Artigo 34, ao tratar da jornada do ensino fundamental, focando a progressiva ampliação.

Art. 34. A jornada escolar no ensino fundamental incluirá pelo menos quatro horas de trabalho efetivo em sala de aula, sendo progressivamente ampliado o período de permanência na escola.

$\S 1$ 으o ressalvados os casos do ensino noturno e das formas alternativas de organização autorizadas nesta Lei.

$\S 2$ O O ensino fundamental será ministrado progressivamente em tempo integral, a critério dos sistemas de ensino. (BRASIL, 1996)

A proposta de escola de tempo integral na LDB/96 foca a ampliação progressiva nas redes, conforme estabelece o Artigo 87, que norteia as metas e definições subsequentes a esta legislação. 0 parágrafo 5을 estabelece:

$\S 5$ ㅇ Serão conjugados todos os esforços objetivando a progressão das redes escolares públicas urbanas de ensino fundamental para o regime de escolas de tempo integral. (BRASIL, 1996)

As Diretrizes Curriculares Nacionais Gerais para a Educação Básica, Resolução no 4, de 13 de julho de 2010 da Câmara de Educação Básica do Conselho Nacional de Educação (BRASIL, 2010) foram definidas na gestão de Francisco Aparecido Cordão. A época, Fernando Haddad estava à frente do Ministério da Educação (MEC) e o executivo era comandado pelo Presidente Luiz Inácio Lula da Silva. Estão organizadas em 60 artigos divididos da seguinte maneira: o título 1 traz os objetivos; o título II as referências conceituais; o título III trata do sistema nacional de educação; o título IV do acesso e permanência para a conquista da qualidade social; o título $V$ da organização curricular: conceito, limites, possibilidades e está subdividido em, capítulo I sobre formas para a organização curricular e capítulo II sobre formação básica comum e parte diversificada

No título VI organização da educação básica, o capítulo I aborda as etapas da educação básica e está subdividido em, seção I educação infantil, seção II ensino fundamental e seção III ensino médio; no capítulo II modalidades da educação básica, a seção I trata da educação de jovens e adultos, a seção II da educação especial, a seção III da educação profissional e tecnológica, a seção IV da educação básica do campo, a seção $V$ da educação escolar indígena, a seção VI da educação a distância e a seção VII da educação escolar quilombola

O título VII aborda os elementos constitutivos para a organização das diretrizes curriculares nacionais gerais para a educação básica e está subdividido em, capítulo I sobre o projeto políticopedagógico e o regimento escolar, capítulo II que trata da a avaliação e está subdividido em seção I avaliação da aprendizagem, seção II promoção, aceleração de estudos e classificação, seção III avaliação institucional e seção IV avaliação de redes de educação básica, o capítulo III trata da gestão democrática e organização da escola e o capítulo IV do professor e a formação inicial e continuada.

A educação em tempo integral é tratada no título $V$, artigo 12 , parágrafos 1 e 2 , estabelecendo que:

Art. 12. Cabe aos sistemas educacionais, em geral, definir o programa de escolas de tempo parcial diurno (matutino ou vespertino), tempo parcial noturno, e tempo integral (turno e contra turno ou turno único com jornada escolar de 7 horas, no mínimo, durante todo o período letivo), 
tendo em vista a amplitude do papel socioeducativo atribuído ao conjunto orgânico da Educação Básica, o que requer outra organização e gestão do trabalho pedagógico.

$\S 1$ 을 Deve-se ampliar a jornada escolar, em único ou diferentes espaços educativos, nos quais a permanência do estudante vincula-se tanto à quantidade e qualidade do tempo diário de escolarização quanto à diversidade de atividades de aprendizagens.

$\S 2$ A jornada em tempo integral com qualidade implica a necessidade da incorporação efetiva e orgânica, no currículo, de atividades e estudos pedagogicamente planejados e acompanhados. (BRASIL, 2010)

As discussões acerca do PNE/14 iniciaram-se nas conferencias estaduais, municipais e regionais que antecederam a I Conferência Nacional de Educação, realizada na cidade de Brasília, em 2010, cujo tema foi, Construindo o Sistema Nacional Articulado de Educação: o Plano Nacional de Educação, Diretrizes e Estratégias de ação. Tais conferencias mobilizaram aproximadamente 3,5 milhões de brasileiros em torno de discussões sobre a educação nacional e a elaboração do atual PNE, sancionado pela Lei no 13.005, de 25 de junho de 2014. Este Plano se configura de maneira bem mais enxuta que o seu antecessor. Seu texto é composto por 14 artigos, 20 metas e 256 estratégias, concebido sob a tutela do então ministro da educação Henrique Paim e, aprovado sem vetos pela Presidenta da República Dilma Roussef.

As metas do PNE de 2014 tratam dos seguintes temas: meta 1 educação infantil (17 estratégias); meta 2 ensino fundamental (13 estratégias); meta 3 ensino médio (14 estratégias); meta 4 educação especial (19 estratégias); meta 5 alfabetização das crianças ( 7 estratégias); meta 6 tempo integral (9 estratégias); meta 7 qualidade da educação básica/ideb (36 estratégias); meta 8 escolaridade média da população de 18 a 29 anos (6 estratégias); meta 9 alfabetização da população com 15 anos ou mais/erradicação do analfabetismo (12 estratégias); meta 10 educação de jovens e adultos, nos ensinos fundamental e médio, na forma integrada à educação profissional (11 estratégias); meta 11 educação profissional técnica de nível médio (14 estratégias); meta 12 acesso à educação superior (21 estratégias); meta 13 qualidade da educação superior/titulação do corpo docente (9 estratégias); meta 14 acesso à pós-graduação stricto sensu/ampliação do número de titulados (15 estratégias). A meta 15 da formação dos profissionais da educação/professores da educação básica A meta 15 da formação dos profissionais da educação/professores da educação básica com formação específica de nível superior (licenciatura na área de conhecimento em que atuam) (13 estratégias); meta 16 formação, em nível de pósgraduação, dos professores da educação básica/formação continuada na área de atuação (6 estratégias); meta 17 equiparação, até o final de 2019, do rendimento médio dos profissionais do magistério das redes públicas de educação básica ao dos demais profissionais com escolaridade equivalente (4 estratégias); meta 18 planos de carreira para os profissionais da educação básica e superior pública de todos os sistemas de ensino/piso salarial nacional para profissionais da educação básica pública - referenciados na lei do piso (8 estratégias); meta 19 gestão democrática da educação (08 estratégias) e a meta 20 trata sobre investimento público em educação pública.

O PNE/14 possui 10 diretrizes, que são: erradicação do analfabetismo; universalização do atendimento escolar; superação das desigualdades educacionais, com ênfase na promoção da cidadania e na erradicação de todas as formas de discriminação; melhoria da qualidade da educação; formação para o trabalho e para a cidadania, com ênfase nos valores morais e éticos em que se fundamenta a sociedade; promoção do princípio da gestão democrática da educação pública; promoção humanística, científica, cultural e tecnológica do país; estabelecimento de meta de aplicação de recursos públicos e educação como proporção do Produto Interno Bruto (PIB), que assegure atendimento às necessidades de expansão, com padrão de qualidade e equidade; 
valorização dos(as) profissionais da educação; promoção dos princípios do respeito aos direitos humanos, à diversidade e à sustentabilidade socioambiental.

Neste Plano Nacional de Educação a educação em tempo integral ganha mais notoriedade em relação as legislações analisadas anteriormente, tanto que há uma meta especifica para esta modalidade de ensino. A meta 6 que trata sobre educação integral determina, "oferecer educação em tempo integral em, no mínimo, cinquenta por cento das escolas públicas, de forma a atender, pelo menos, vinte e cinco por cento dos(as) alunos(as) da educação básica." (BRASIL, 2014). O Plano apresenta 9 estratégias para o cumprimento desta meta, que são:

6.1. Promover, com o apoio da União, a oferta de educação básica pública em tempo integral, por meio de atividades de acompanhamento pedagógico e multidisciplinares, inclusive culturais e esportivas, de forma que o tempo de permanência dos(as) alunos(as) na escola, ou sob sua responsabilidade, passe a ser igual ou superior a sete horas diárias durante todo o ano letivo, com a ampliação progressiva da jornada de professores em uma única escola; 6.2. Instituir, em regime de colaboração, programa de construção de escolas com padrão arquitetônico e de mobiliário adequado para atendimento em tempo integral, prioritariamente em comunidades pobres ou com crianças em situação de vulnerabilidade social; 6.3. Institucionalizar e manter, em regime de colaboração, programa nacional de ampliação e reestruturação das escolas públicas, por meio da instalação de quadras poliesportivas, laboratórios, inclusive de informática, espaços para atividades culturais, bibliotecas, auditórios, cozinhas, refeitórios, banheiros e outros equipamentos, bem como da produção de material didático e da formação de recursos humanos para a educação em tempo integral; 6.4. Fomentar a articulação da escola com os diferentes espaços educativos, culturais e esportivos e com equipamentos públicos, como centros comunitários, bibliotecas, praças, parques, museus, teatros, cinemas e planetários; 6.5. Estimular a oferta de atividades voltadas à ampliação da jornada escolar de alunos(as) matriculados nas escolas da rede pública de educação básica por parte das entidades privadas de serviço social vinculadas ao sistema sindical, de forma concomitante e em articulação com a rede pública de ensino; 6.6. Orientar a aplicação da gratuidade de que trata o art. 13 da Lei no 12.101, de 27 de novembro de 2009, em atividades de ampliação da jornada escolar de alunos(as) das escolas da rede pública de educação básica, de forma concomitante e em articulação com a rede pública de ensino; 6.7. Atender às escolas do campo e de comunidades indígenas e quilombolas na oferta de educação em tempo integral, com base em consulta prévia e informada, considerando-se as peculiaridades locais; 6.8. Garantir a educação em tempo integral para pessoas com deficiência, transtornos globais do desenvolvimento e altas habilidades ou superdotação na faixa etária de quatro a dezessete anos, assegurando atendimento educacional especializado complementar e suplementar ofertado em salas de recursos multifuncionais da própria escola ou em instituições especializadas; 6.9. Adotar medidas para otimizar o tempo de permanência dos alunos na escola, direcionando a expansão da jornada para o efetivo trabalho escolar, combinado com atividades recreativas, esportivas e culturais. (BRASIL, 014) 
Além desta meta a educação em tempo integral aparece novamente na estratégia 17 da meta 1, que trata da educação infantil. Tal estratégia define: "estimular o acesso à educação infantil em tempo integral, para todas as crianças de zero a cinco anos, conforme estabelecido nas Diretrizes Curriculares Nacionais para a Educação Infantil." (BRASIL, 2014).

\section{DISCUSSÃO}

Segundo Saviani (2011, p. 179-180) as políticas educacionais são instrumentos da ideologia dominante no período de sua elaboração e, segundo ele, a partir dos anos de 1990 as políticas educacionais são marcadas por uma "racionalidade financeira". Portanto, ao considerarmos que, as legislações analisadas foram elaboradas a partir da segunda metade dos anos de 1990, devemos ponderar que seus textos estão marcados, as vezes com maior ou menor intensidade, por esta ótica.

Neste tocante, é importante termos em mente que há diferentes concepções e justificativas para a ampliação da jornada escolar, Cavaliere (2007) diz que há atualmente quatro concepções de educação em tempo integral predominantes no Brasil, que podem apresentar objetivos e justificativas distintos ou, até mesmo, aparecerem diluídas em uma mesma experiência. São: a concepção democrática, que pensa em uma escola democrática e emancipatória; a concepção autoritária, que enfatiza a rigidez, a rotina e vê a escola como um lugar de prevenção ao crime; a concepção multissetorial, estimula parcerias com ONGs e outras instituições para que a educação açnteça em ambientes fora da escola; e a concepção assistencialista, que tem um foco maior no acolhimento do que na educação, vê a escola como um lugar de "atendimento" aos mais carentes.

Pudemos constatar que a LDB/96 não traz nenhuma definição concreta, nem conceituações sobre escola de tempo integral, o que se encontra são alusões futuras. Entretanto, é importante destacar que, estar presente nas definições da LDB é um importante passo para a educação em tempo integral no Brasil.

Ao examinar as Diretrizes Curriculares para a Educação Básica observamos que a legislação estabelece o tempo mínimo que o aluno deve permanecer na escola de tempo integral e salienta a importância de se repensar o currículo e as atividades pedagógicas, visando um bom uso deste tempo. Porém, a legislação deixa em aberto a possibilidade de turno único ou turno e contra turno, e possibilita a utilização de diferentes espaços educativos.

Constatamos ainda que, tanto a LDB/96 quanto as Diretrizes Curriculares para a Educação Básica, utilizam a nomenclatura escola de tempo integral ao se referirem a esta modalidade de ensino. Outo ponto concomitante é o fato de ambas atribuírem aos sistemas de ensino a responsabilidade por sua implementação.

$\mathrm{O}$ PNE/14 foi a legislação mais recente, dentre as analisadas, e também foi o texto que dedicou mais espaço para tratar da educação em tempo integral. Nele esta modalidade de ensino ganhou maior expressividade e foi aborda de maneira mais concisa, definindo metas, prazos e estabelecendo estratégias. O texto estabelece que a união deve apoiar e colaborar com a implementação da educação em tempo integral e, estimula parcerias articuladas entre a escola e entidades privadas. Vale ressaltar que, diferente das legislações anteriores, o PNE/14 não utiliza o termo escola de tempo integral, e sim, educação em tempo integral.

\section{CONCLUSÃO}

Com este trabalho observamos que, em algumas legislações a educação em tempo integral recebeu maior destaque, em outras menor, contudo, foi abordada em todos os textos. Constatamos ainda, que as legislações mais recentes destinaram maior espaço para abordar esta modalidade de ensino. 
Entretanto, as legislações apresentam estratégias e indicações amplas mas, deixam aberto as diferentes interpretações na implementação desta modalidade de ensino e, como vimos, os objetivos, as justificativas e os princípios podem ser antagônicos de acordo com o conceito que se tem de educação em tempo integral, já que, todas as legislações deixaram o seu desenvolvimento a cargo dos sistemas municipais e estaduais de ensino.

\section{REFERÊNCIAS}

BRASIL. Lei no 9.394, de 20 de dezembro de 1996. Estabelece as Diretrizes e Bases da Educação Nacional. LDB Lei de diretrizes e bases da educação nacional, Brasília, 25 p., 2016 /Série legislação; n. 263/ Versão PDF.

BRASIL. Resolução no 4, de 13 de julho de 2010. Brasília, 2010. Define Diretrizes Curriculares Nacionais Gerais para a Educação Básica. Disponível em: <http://portal.mec.gov.br/index.php?option=com_docman\&view=download\&alias=6704-rceb00410-1\&category_slug=setembro-2010-pdf\&Itemid=30192> Acesso em: 05 ago. 2017.

BRASIL. Lei no 13.005, de 25 de junho de 2014. Aprova o Plano Nacional de Educação. Plano Nacional de Educação 2014-2024, Brasília, 86 p., 2014. /Série legislação; n. 125/ Versão PDF.

CAVALIERE, Ana Maria. Tempo de escola e qualidade na educação pública. Educação e Sociedade, Campinas, v. 28, n. 100, p.1015-1035, out. 2007, https://doi.org/10.1590/S0101-73302007000300018.

CELLARD, André. A análise documental. In: POUPART, Jean et al. A pesquisa qualitativa: enfoques epistemológicos e metodológicos. 2. ed. Petrópolis: Vozes, 2010. p. 295-316. Tradução de Ana Cristina Arantes Nasser.

COELHO, Lígia Martha Coimbra da Costa. História(s) da educação integral. Em aberto, Brasília, v. 22, n. 80, p.1-165, abr. 2009.

ESQUINSANI, Rosimar Serena Siqueira. A trajetória da escola em tempo integral no Brasil: revisão histórica. In: Congresso Brasileiro de História da Educação, 5. : 2008 : Aracaju, Sergipe. O ensino e a pesquisa em história da educação: 5. Congresso Brasileiro de História da Educação - São Cristóvão: Universidade Federal de Sergipe; Aracaju: Universidade Tiradentes, 2008.

SÃO PAULO (Estado). Secretaria da Educação. Informações básicas do Programa Ensino Integral. São Paulo, [2014]. Disponível em: <http://www.educacao.sp.gov.br/a2sitebox/arquivos/documentos/727.pdf>. Acesso em: 11 nov. 2016.

SAVIANI, Dermeval. Da nova LDB ao Fundeb. 4. ed. Campinas: Autores Associados, 2011. 317 p. (Coleção educação contemporânea). 